\title{
Migration, Identity and Wellbeing in Melbourne Australia - The Idea of being Greek in Diaspora
}

\author{
By Maria-Irini Avgoulas ${ }^{*} \&$ Rebecca Fanany ${ }^{ \pm}$
}

\begin{abstract}
Both maintenance and transmission of Greek cultural identity are central to people of Greek descent living in diaspora, regardless of whether the individuals involved are immigrants or the descendants of immigrants. The 'idea of being Greek' often represents a positive resource for personal and group identity, even though what constitutes being Greek may be different depending on the cultural lens through which it is viewed in the experience of each generation. Nonetheless, core domains associated with the concept of being Greek include the Greek language, the Greek Orthodox religion and various daily cultural practices. This paper will discuss findings across a number of recent studies undertaken in Melbourne, Australia taking an emic and etic perspective that all utilize the emergent methodology of narrative ethnography to explore migration, identity and wellbeing in the Greek community as well as the idea of being Greek in diaspora. The results suggest that there are emotional benefits associated with cultural identity and overall positive wellbeing and that, for those living in diaspora, whether migration was planned or not, a cultural community, cultural activities and membership in a distinct group are positive resources in fostering social connectedness. From a social perspective on health, this extends beyond the physiological/clinical elements of health and wellbeing and emphasizes the various social and intangible benefits of positive outlook and the very significant role that culture, and cultural practices play in the group social context by contributing to the perception of health and wellbeing in the Greek diaspora community across generations.
\end{abstract}

Keywords: Culture, identity, wellbeing, Greek identity, migration

\section{Introduction and Background}

Identity is a vital marker of who we are, regarless of age or gender, both as individuals and for populations in general. This is particularly, the case for those individuals and/or groups living in diaspora, who may be experiencing issues of displacement, a loss of connection and a sense of not belonging. The idea of being Greek in diaspora will be discussed in this paper and domains such as the Greek language, Greek Orthodox religion and various Greek cultural practices will be further explored and elucidated. Findings will be presented from three studies undertaken between 2011and 2016 in Melbourne, Australia. All participant information has been removed, and participants are referred to by number to protect their privacy. Ethics approval was sought and received for each of the

\footnotetext{
*Associate Lecturer, La Trobe University, Australia.

${ }^{ \pm}$Associate Professor, Central Queensland University, Australia.
} 
studies, which conform to the Australian national guidelines on research ethics. This paper takes an emic and etic perspective using the approach of narrative ethnography. One of the authors is a Greek Australian researcher who was able to use her insider experience to investigate issues relating to migration, identity and wellbeing in the Greek community as well as the idea of being Greek in diaspora.

\section{Methodology}

This paper discusses three qualitative studies that were undertaken over five years. The data generated by all the studies was collected through in depth interviews in either English or Greek. In 2011, the first study entitled 'Cultural Understanding of Health and Adjustment to Cardiovascular Disease among the Greek elderly' was undertaken. A total of 13 participants over the age of 60, took part in this project. All of the participants were recruited from the Fronditha Care activity group. This study specifically considers at the health beliefs of elderly Greek Australians and the way they understand health and disease. Of particular interest was the way older Greek Australians conceptualize cardiovascular disease and seek medical care in the context of their specific cultural views and attuites towards illness and wellbeing. In 2012, the second study entitled 'Health Beliefs and Practices in Three Generations of Greek Australian Women in Melbourne' was undertaken as part of the doctoral program of one of the authors (Avgoulas). This research explored health beliefs and practices in three generations of Greek Australian Women in Melbourne. In total 48 participants took part in the study, representing the immigrant, first generation, and second generation in Australia. Each generation spoke about the meanings they attributed to various life experiences associated with health, illness and wellbeing as they understood and experienced them. Finally, in 2016, the third study entitled 'Greek dancing as an aspect of cultural identity and wellbeing' was carried out. A total of 19 participants from the Manasis School of Greek Dance and Culture in Melbourne took part in this study. The aim of this study was to understand the motivations and aims of participation who took part in Greek dancing while living in Diaspora.

\section{Literature Review}

Humanistic psychology came about in the mid $20^{\text {th }}$ century, as a way of addressing perceived limitations in the theories of Freud in his work on psychoanalysis and Skinner in his studies of behaviorism (May 2000; Luce 1992). One of the main proponents of humanistic psychology was Abraham Maslow who is best known for his work on a set of needs that he proposed drove human behaviour in order of decreasing priority but increasing complexity. Maslow's hierarchy has been extremely influential as a means for understanding how individuals might achieve self-actualization and maximum potential (see Maslow, 2012). Like Maslow's, much of the work in the discipline focuses on the concept of the self which is taken to be unique. This idea was built upon by George Kelly 
(1991) in his theory of "personal construct"and Carl Rogers (1951) who was interested in the development of personality. His view holds that the individual strives for self-actualization, self-maintenance, and self-enhancement in the effort to create a total self. While one of the main strengths of humanistic psychology has been acknowledged to be its focus on the role of the individual who is seen as having the ability to take control of his or her own life, it has also been criticized as being too subjective and difficult to objectively define or quantify because of the emphasis on unique experience (Schneider et al. 2015). Nonetheless, humanistic psychology remains important because of its emphasis on individual choice and responsibility. It also supports the development of the individual within a specific environment, that fits well with with influential models and approaches in the study of health and disease (see, for example, Glanz et al. 2015).

One of the more influential sub-disciplines of positive psychology that has emerged since its inception has been positive psychology. Positive psychology focuses on the things that are viewed as making life worth living (Peterson 2006). As a discipline, its aim is to emphasize human strengths, rather than weaknesses, with special concern for positive states (happiness, joy, love), positive states (gratitude, resilience), and positive institutions. The origins of the field lie in the work of Martin Seligman, who developed the theory of learned helplessness based on his study of people with depression (Abramson, et al. 1978). One of the most significant benefits of positive psychology to the individual has been seen as its focus on the possibility of changing perspective which can lead to change in life satisfaction and quality of life. Among the findings of positive psychology that are relevant to the studies reported here relate to the importance of religion and spirituality; the centrality of strong social relationships as protection against the impact of life's misfortunes; and that empathy and compassion are as important as critical thinking in finding meaning and happiness in life (Lopez and Snyder 2009). While having many benefits for individuals in the context of therapy, positive psychology has been critizied for being too individually focused, placing too much emphasis on self-reporting, and potentially culturally and ethnocentrically biased.

Despite such criticisms, Seligman's (20111) PERMA model has been an influential tool.

In understanding individual well-being and life satisfaction. This model contains five factors that Seligman suggests are required for happiness. They are: positive emotion, engagement, relationships, meaning, and accomplishments. Seligman (2012) later updated his theory, suggesting that happiness can be analysed as emcompassing three separate but related concepts, namely positive emotion, engagement and meaning, with the implication that these three of the original five PERMA factors are the most crucial in longterm happiness and a sense of well-being. The PERMA model provides a useful framework for understanding the views of the participants in the three studies that contribute to this paper. It is notable that the individuals involved overall show great contentment and satisfaction with their life and tend to perceive their experiences in a positive light. This outlook is shared across the generations and is especially significant among the older participants who experienced the hardshops of 
immigration and integration into the Australian context firsthand. The perspective associated with their Greek background and culture seems to have a great deal to do with this outlook on life, and positive psychology provides a means to better understand the dimensions of their view.

\section{Findings}

Many of the participants described a strong belief in God's will as significant in their life experiences along with the certainty that divine assistance was a real possibility. One older woman explained:

"God protected my son, he had cancer, was very sick. The doctors were giving me no hope. I prayed to the Virgin Mary and asked for God's help. My son's health returned. It was his fate and God's will for him to be okay." (Participant 8)

Younger individuals who were born in Australia expressed similar views about the importance of their faith. One middle aged participant described the things she hopes her children will maintain in future generations:

"I would like them to believe in Christ, the Virgin Mary and God, in our religion and culture." (Particiapnt 1)

Regardless of age, the participants felt that their religious beliefs were central to their identity as Greeks and that the be;life in the principles of the Greek Orthodox faith set them apart as a cultural group within the larger Australian context. One expressed this feeling as follows:

"Being Greek and of Greek Orthodox religion is who we are. We can relate to one another, the language, culture, and belief system." (Participant 6)

While a majority of the participants were born in Australia and, at the time this research was carried out, the immigrant generation had been in the country for decades, individuals of all ages perceived themselves as members of a distinct group that was different from the mainstream of the Australian population. For older individuals, this was associated with markers of Greekness that included origin in a specific location in Greece, speaking Greek as their first language, and the maintenance of Greek customs. For the younger individuals who had been born in Australia, many of these same markers of identity remained important, although their nature characterized the experience of their generation. The first Australian born generation, now middle aged, tend to be bilingual in Greek and English and share many of the attitudes and day to day behaviour as their parents who were immigrants. Their experience has often been colored by the difficulties their older relatives experienced as well as by their own perceptions of racism toward people who were not of English-speaking background. The younger participants, who represent the second Australian generation, tend to be English speakers who may speak some Greek but who generally do not have the facility in 
the language that their parents do. Their experience reflects the modern Australian context and is not significantly different from that of other people their age. They have grown up in the period of Australian multiculturalism where policy and institutions are premised on the acceptance of immigration and the fostering of social cohesion accompanied by support for linguistic and cultural practices that are different from the mainstream (Soutphommasane 2016). Nonetheless, the perception that they are part of a distinct social and cultural group was very strong across the generations in this study.

Among the older individuals, their Greek identity was an integral part of their self perception that they strived to maintain against challenges from the larger Australian environment.

"My friends base is 95\% Greek. I don't venture out too much, out of my culture. Not that I don't want to, I just can't assimilate. I don't identify with anything outside the Greek culture." (Participant 5).

"I have maintained the Greek way, even after all these years. I have not taken on the Australian way." (Participant 14).

Other participants, who were born in Australia, perceived their Greek identity in the context of the Greek Australian culture that they had learned from older relatives. While there can be no doubt that this cultural context has developed and evolved and, as many participants know firsthand, is now very different from what they have experienced when visiting Greece, it nonetheless represents truye "Greekness" to them. At its heart is use of the Greek language, even in limited contexts, and participation in activities and practices they associate with being Greek in Australia.

"You hear about Greece all your life. That's your heritage, your culture." (Participant 10)

"It [remaining Greek] was easy because we could speak Greek with other Greek people. If there were not so many Greek people, if there was an area with only one or two Greek families, then it would be difficult." (Participant 2)

"You need to be active and do Greek things to call yourself Greek. You need to connect with what is Greek." (Participant 7)

Even younger individuals, despite being native speakers of English and fully integrated in the Australian lifestyle, tended to view their social experience in terms friends of the same cultural background as opposed to other people they might know.

"[I have] definitely more Greek friends. Some have been family friends, and then you're friends with them as well. At school as well, everyone flocked together. We stuck with each other, because we are more like minded, we understand each other, and we can use the Greek slang in conversation. I think it would be familiarity because we have common grounds." (Participant 5) 
"I have definitely more Greek friends. It's lucky, I guess, and I get along better with my Greek friends. We have things in common." (Participant 8)

"At school, all my friends are not Greek, and, out of school, I have more Greek friends. I feel I connect more to my Greek friends and we understand each other better"." (Participant 8)

Greek dancing continues to be a popular social activity in the Melbourne community. The existence of dancing schools and groups can be traced back to the influence of the original immigrants who felt that this form of cultural expression was relevant in the Australian diaspora and encouraged their children to take part. Today, the forums for Greek dancing are well established and have come to have meaning for individual sof all ages, although the idea that this activity is of special importance to older people remains common.

"Social aspects, making new friends and also physical activity. I have grown up in my family with dancing, my parents from a young age when I was in a stroller would take us to dinner dances. I have grown up in dancing and Greek music, and from a young age I was in a dancing group." (Participant 7 )

"Performance is why we do this, the performance and the look in the eyes of the audience, they are amazed. Especially the old people they feel very connected. My family is very supportive of my dancing and has always been." (Participant 14)

"You can find the exercise part through the other hundreds of sports that exist, however with the Greek part you don't find that. I've never found that anywhere apart from Greek School, but not really, it's not the same, its more unifying even in the literal sense of holding hands." (Participant 18)

"Even though they [elders] are not dancing when they are audience, it will provide them with joy. They are so proud, even when they see their grandchildren but it's the same thing when they see strangers. We are automatically connecting and bonding, it could be a song, a dance, a memory. It's our culture and where they grew up." (Participant 14)

While the older participants were very concerned to ensure that their children and grandchildren knew and understood the Greek culture as their elders saw it, younger individuals were equally concerned about their ability to maintain the cultural context in which they had been brought up. In many cases, a central element of this concern was the loss of facility in Greek, which for older people, has tended to be the single most important marker of Greek identity. For many members of the Australian born generations, however, the difficulty of maintaining a separate cultural identity without language was clear.

The desire for continuity was stressed by older individuals.

"I am a traditional Greek person and I have tried to maintain the Greek way here in Australia. I feel nostalgia for Greece and I tell my children, when I die, I want to be buried in Greece, in Greek soil." (Participant 14) 
"My children were part of a dancing group and, when they danced traditional dances, I felt pride. I sent them to Greek school to learn the language." (Participant 8)

The Australian born generations recognized the difficulty inherent in cultural maintenance in the face of of pressures from the Australian mainstream. Members of the first Australian born generation saw this chlannege as a responsibility placed on them by their parents and reflecting their elders experiences of migration.

"The Greek language is an association to being Greek. That's the most important [thing] that I want to maintain and continue. It will be challenging if I marry a nonGreek person." (Participant 14)

'Yes, it's important because it's who you are. You're born here but you're Greek and you want to put it into your kids." (Participant 3)

"It's my identity. It's who I am, and I want to pass it on to my children because I know, with every generation, you lose quite a lot of it and more if they marry outside of the culture, which I'm hoping doesn't happen. We're sounding a lot like our parents. I want my children to marry someone who is Greek Orthodox." (Participant 5)

“It's important to maintain religion, language and culture." (Participant 4)

The younger individuals, who are members of the second Australian born generation, feel the pressure to remain "Greek" as well but are also aware of their integration into the English-language context and the role of their elders in maintaining Greek identity in diaspora. One younger individual expressed this dilemma as follows:

"I love my Greek heritage and I want to carry it on, but if my Greek isn't great, I'm worried that my kids won't speak great Greek. Or even if I teach them and send them to Greek school, they would be $3^{\text {rd }}$ generation, and I'm worried about losing it. I always say to my mum, I don't want to lose it. I like saying I'm Greek-Australian and, when people ask me what nationality, I am, I am Greek. I'm Greek defiantly. I'm proud to be Greek and I'm scared to lose the traditions. Without my grandmother, how would I know? " (Participant 6)

Another younger individual reflected on the lack of knowledge and cultural depth felt by many younger people of Greek background and the need to address this by active participation in the Greek community.

"Maintaining identity is so important and essential to keep our culture alive. We need to participate and do Greek things and speak Greek and saying ylayló [grandmother] and $\pi \alpha \pi \pi \circ v$ [grandfather] isn't enough. In order to keep the Greek title, we need to participate and be a member, make a conscious effort." (Participant 19) 


\section{Discussion}

The experience of people of Greek background in the Australian diaspora is notable for the degree of acculturation and success in the English-speaking context that has characterized the community (Tamis 2005). This is particularly significant because of the circumstances that brpoght the majority of Greek immigrants to Australia following World War II and the Greek civil war. Largely, these individuals had little formal education and few job skills. Adjustment to their new social and cultural context, which included a need to use the English language, remains a common bond among older people in the community and a source of shared understanding about the importance of community and social networks encompassing people of similar background and heritage. For the first and second Australian born generations, pride in their Greekness is the norm, despite a gradual lessening of specifically Greek practices and way of life. The change to Australian ways has been accompanied by a loss of ability to use the Greek language in all domains. Many of the youngest members of the Greek community no longer speak Greek, if language facility is measured by the ability to communicate in all contexts with ease and naturalness, and are native speakers of English. Interestingly, the definition of what it means to "speak Greek" seems to have shifted and has specific dimensions that reflect the experience of each generation, ranging from speaking a most exclusiovely Greek among members of the immigrant generation, bilingualism among members of the first Australian born generation, to speaking almost exclusively English with the use of limited Greek words and terms among the youngest members of the community. Nonetheless, the individual swho took part in this study, despite recognizing current problems and challenges for the future, are uniformly optimistic about the continued existence of a Greek community in Melbourne and express happiness and satisfaction with their life and identity as Greek Australians, or Greeks in Australia as many of them choose to see themselves.

In their perceptions, it is possible to discern the three components of happiness as described by Seligman (2012): positive emotion, engagement and meaning. Across the generations, significant positive emotion was obtained from the cultural heritage of the participants. Doing Greek things and being Greek, regardless of the specific form these things took for any given individual, was a source of pride, contentment, and enjoyment and was seen as a way of contributing to the community in an important way. Similarly, individuals of all ages and experience tended to be heavily engaged in the community, through attendance at Greek institutions such as church or Greek school, by taking part in Greek activities such as traditional dancing groups, or in personal social networks of friends and family. This last was extremely important to participants of all ages who distinguished in their feelings between their social relationships with other people of Greek background and those with individualas from other cultural groups. Every elements of their perceived Greek identity was meaningful to the participants, although it should be noted that the nature of the main elements of this identity did differ among individual sof different ages. As noted above, for the immigrant generation, identity centered on maintenance and preventing change in 
linguistic, religious, cultural, and social behaviour, with their experience in the Greece of their youth providing the standard against which this change was measured. For younger individuals who were born in Australia and who were integrated into the English-speaking mainstream, Greek identity focused on certain specific elements of behaviour that existed alongside and in conjunction with other behaviors that were not different from those of other Australians. Nonetheless, the perception of meaningfulness of their Greekness was strong in individuals of all ages and was frequently expressed, both directly and indirectly.

In light of this situation, it is perhaps not surprising that the participants in this study described feeling happy, among friends of Greek background, participating in Greek activities like dancing and religious occasions, using the Greek language, and eating Greek food. In addition to the specific elements that constitute Greek culture in Australia, the younger individuals had learned a sense of pride and developed a sense of superiority of their culture from the older members of the community, which was central to their views on the meaning and importance of cultural maintenance and which also served as a source of well-being. These attributes were perceived as a source of strength by all the individuals involved, again suggesting the relevance of the principles of positive psychology in understanding the experience of Greek diaspora in Australia. This experience is a personal perspective of each individual involved but also has an important shared dimension that reflects the experience of each generation in its own social and cultural context. In this sense, the personal aspect of the experience is central and can be understood through an analysis of the emotions associated with Greekness by those involved.

\section{Conclusion}

The experience of migration that underpins the shared cultural experience of the Greek diaspora in Melbourne provides a strongly influential source of generally positive emotion for its members that is based on a perception of Greek identity in the English-speaking context of Australia. The positive associated with identity are recognized and appreciated by members of the community of all ages and have persisted despite successful integration into the social and cultural mainstream and exist even among older individuals who experienced hardship as a context of migration, cultural disruption, racism, and perceived status as outsiders. Younger individuals tend to be very much aware of the influence on their thinking from these older relatives, but it is notable that the elements of the experience of migration that have been ytransmitted are largely positive and have not focused on the negative elements of the migration experience. As a result, the conceptualization of Greek identity in Melbourne has come to result in the emergence three related factors suggested to give rise to happiness within the perspective of positive psychology, namely positive emotion, engagement and meaning. This circumstance may be related to the notes successful integration of people of Greek originin to Australian society, which is an important characteristic that sets this cultural community apart from some of the others that make up the modern 
Australian nation. As such, the Greek community can be seen as a successful example of identity maintenance and development within the context of multiculturalism whose experience and perspective may suggest new insights into the understanding of migration, life in diaspora, and well-being.

\section{References}

Abramson LY, Seligman MEP, Teasdale JD (1978) Learned helplessness in humans: Critique and reformulation. Journal of Abnormal Psychology 87: 49-74.

Glanz K, Rimer BK, Viswanath K (2015) Health Behavior: Theory, Research and Practice. Jossey Bass.

Kelly G (1991) The Psychology of Personal Constructs. Routledge, London. Lopez CR, Snyder SJ (2009) Oxford Handbook of Positive Psychology. Oxford. Luce JV (1992) An Introduction to Greek Philosophy. NY: Thames \& Hudson. Maslow AH (2012) A Theory of Human Motivation. Start Publishing.

May H (2000) On Socrates. Belmont, CA: Wadsworth. IBSN 978-0-534-57604-2 Peterson C (2006) A Primer in Positive Psychology. Oxford.

Rogers C (1951) Client-centered therapy: Its current practice, implications and theory. London: Constable.

Schneider KJ, Pierson JF, Bugental JFT (2015) The Handbook of Humanistic Psychology: Theory, Research and Practice. Sage.

Seligman M (2012) Flourish: A Visionary New Understanding of Happiness and Wellbeing, Atria.

Soutphommasane T (2016) The Success of Australia's Multiculturalism. Australian Human Rights Commission, https://bit.ly/2SCSbSv.

Tamis AM (2005) The Greeks in Australia. Cambridge University Press. 